Original Research Paper

\title{
Fabrication and Tensile Property Analysis of Polymer Matrix Composites of Graphite and Silicon Carbide as Fillers
}

\author{
${ }^{1,2}$ Vikram G. Kamble and ${ }^{3}$ Naveen Kumar L. \\ ${ }^{1}$ Research Fellow, Proof and Experimental Establishment (DRDO), Balasore, Odisha-756025, India \\ ${ }^{2}$ St Joseph Engineering College, Mangalore, Karnataka-575028, India \\ ${ }^{3}$ MTech Scholar, Sri Jayachamarajendra College of Engineering, Mysore, Karnataka -570006, India
}

\author{
Article history \\ Received: 19-09-2015 \\ Revised: 26-11-2015 \\ Accepted: 27-11-2015 \\ Corresponding Author: \\ Vikram G. Kamble \\ Research Fellow, Proof and \\ Experimental Establishment \\ (DRDO), Balasore, Odisha- \\ 756025, India and \\ St Joseph Engineering College, \\ Mangalore, Karnataka-575028, \\ India \\ Tel: +919901447793 \\ Email: iknowvikramkamble@gmail.com
}

\begin{abstract}
In a world there is ever-increasing demand for new materials, composite materials finds the topmost spot. Here in this work an attempt has been made to study the mechanical properties of Glass and Vinyl Ester composites with and without fillers. Laminates are prepared by Hand Layup technique with changing the volume percentage of Vinyl Ester and fillers in each. The laminates prepared are subjected to tensile test and systematically analyzed to study the behaviour and variation of properties with respect to their composition. The results obtained from the tests have been documented with great detail.
\end{abstract}

Keywords: Tensile Strength, PMC's, Hand Layup Process, Fillers

\section{Introduction}

Polymers and their composites are being used increasingly because of their good strength and low density. The advent of new technologies has increased the demand for superior materials for tribological applications like bearings, cams, gears, chutes, guides, etc (Pande et al., 1998). PMC's exhibit excellent frictional and wear characteristics even without external lubrication and can provide maintenance free operation, excellent corrosion resistance and operate with low noise emission due to good damping properties (Cha'o-Kuang and Tzu-Li, 1997). The knowledge of the relations between material parameters and tribological performance is important in the determination of strength and wear rate of the composite (Ismaila and Rozman, 1998). The characterization of engineering properties is a complex issue for fiberreinforced composites due to their inherent anisotropy and in homogeneity (Suresha, 2003). In terms of mechanical properties, advanced composite materials are evaluated by a number of specially designed test methods. These test methods are mechanically simple in concept but extremely sensitive to specimen preparation and test-execution procedures, often requiring complex data reduction analysis (Unal and Mimaroglu, 2004; Varada Rajulu et al., 2002). Auto clave based methods and to evaluate the Mechanical and Tribological properties of same using experimental methods as well as simulation methods through analytical and computational methods (Eldera, 1966). The properties of a composite material depend on the properties of the constituents, geometry and distribution of the phases. The contribution of a single constituent to the overall properties of the composite is determined by the concentration of the constituent, Volume fraction or weight fraction in that composite (Kalthoff, 2004). Experimental methods consists of tests methods involving in extraction of Mechanical property such as Tension test. Simulation methods consist of analytical as well as computational methods to validate experimental results of polymer composites by considering anisotropy and non homogeneity in their material properties (Swaminathan et al., 2007). Glass is generally a good impact resistant fibre but weighs more than carbon or mid. Glass fibres have excellent characteristics, equal to or better than steel in certain forms. The lower modulus requires special design treatment where stiffness is critical. Composites made from this material exhibit very good electrical and thermal insulation properties. Glass fibres are also transparent to radio frequency radiation and are used in antenna applications (Stevanovica et al., 2003). These composite materials are defined as material systems consisting of mixture of or combination of two or more micro constituents insoluble in each other and differing in form and or 
material composition (Kamble et al., 2015). The concept of composites such as fiber reinforced composites had its origin in nature for example in old trees, we can see the use of composites by the mankind in the weight history and even today in the continuing quest for improved performance such as less weight, more strength and lower cost: Composites are widely used in many applications as they satisfy the present day criteria for materials (Cybulskaa and Goswamib, 2001; Wu and Hahn, 1998). E-Glass has lower alkali content and stronger than AGlass (alkali), it has good tensile and compressive strength, stiffness, good electrical properties and relatively low cost but impact resistance is relatively poor. E-glass is the most common form of reinforcing fibre used in composites (Surendranathan et al., 2008).

\section{Objective of the Work}

The objective of the work is to fabricate polymer composite material using graphite and silicon carbide fillers and to investigate its mechanical tensile property. The manufacturing and fabrication of polymer composite material is done by Hand lay-up method.

\section{Specimen Preparation}

\section{Fabrication Processes}

Reinforced plastics composites are a combination of a resin matrix, fibres and fillers. Which when cured produce a solid structure. The characterization of the desired product (such as size, shape and quantity) determines the method by which the basic holding blocks are combined and moulded. By varying the resin/glass ratio, the type and ratio of reinforcement, the type of resin and the type and amount of fillers, we can significantly alter (control) the physical properties. The variability of product composition and the latitude in size and design possibilities, enables a hand lay-up with vacuum bagging technique part be tailored to economically fit its desired function. The hand layup laminating procedure indicated in Fig. 1.

In the present work specimen were fabricated using hand lay-up and hydraulic press technique hence the procedure employed to prepare specimen is explained in detail.

\section{Fabrication of Laminates Using Hand Lay-Up}

- E-Glass Weave style: $2 \times 2$ twill Cross breaking strength: 6 to $7 \mathrm{~kg} / \mathrm{mn}^{2}$ Aerial density: 280 to 285 Gsm Thickness: 0.21 to $0.24 \mathrm{~mm}$ Finish type: FK 144 Areal Density: 8 Mil

- Matrix Vinyl ester Resin Amine Hardener The Resin and the Hardener are mixed in the ratio of 100:10. Catalyst: Methyl ethyl ketone peroxide Accelerator: Cobalt napthanate Promoter: N-N dimethyl aniline
Steps Involved in Fabrication of the Composite Laminate

Step 1: Preparation of matrix. The matrix contains a resin and hardener, which are mixed thoroughly by electric stirring process till they get mixed uniformly. The fiber weight fraction $=0.65$ Weight of resin system $=$ Weight of fabric $\times$ Matrix weight percentage. Both the resin and the hardener are mixed in the ratio of 100:10 at room temperature. The resin system is ready for hand lay-up technique,

\section{Typical Calculation of Resin System}

- $\quad$ Fibre weight fraction $=0.65$

- Dimension of each layer of glass fabric $=400 \times 400 \mathrm{~mm}$

- Number of layers $=8$ layers

- Weight of fabric ( 8 layers of $400 \times 400 \mathrm{~mm}$ size $)=$ $864 \mathrm{~g}$

- Matrix weight percentage $=45 \pm 1$ (for without filler)

- Weight of resin system $=$ Weight of fabric $\times$ Matrix weight percentage $=864 \times 0.45=388 \mathrm{~g}$ Resin: Hardener $($ by weight $)=100: 10$

- Weight of Hardener $=38 \mathrm{~g}$

The interaction of components at the phase boundaries, which is also associated with the existence of a thick interface, known also as the inter phase; this is often considered as a separate phase, controlling adhesion between the components.

The method of fabrication both the resin and hardener are mixed at room temperature. The resin system is ready for use to prepare laminates by hand lay-up technique:

Step 2: Hand Lay-up Technique: The procedure involved in fabrication of laminate using hand lay-up technique is outlined below:

- The stone surface table was cleaned with acetone

- Wax as releasing agent was applied on the surface

- Glass fabric was cut to required size and number of layers

- $\quad$ Requirement of resin system was calculated based on the weight of fabric

- Quantity of resin and hardener required was calculated

- The surface table was first covered with a Teflon sheet

- Resin is applied onto the Teflon cloth with a brush

- One layer of glass fabric was kept on top of Teflon cloth and soaked with resin

- Subsequently remaining layers of glass fabric as per requirement were placed on top of the soaked fabric one by one and wetted with resin using a brush

- The wet layers were covered with a Teflon sheet, which acts as releasing layer

- The system was then ready for Hydraulic press 


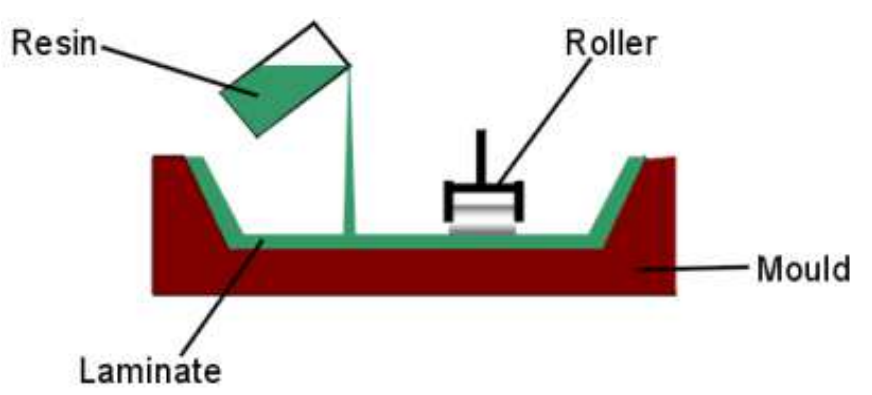

Fig. 1. Hand lay-up technique

Table 1. Testing compositions and calculations

\begin{tabular}{|c|c|c|c|c|}
\hline Percentage of filler material & Matrix (\%wt) & Resin & Filler (Graphite/SIC) & Glass \\
\hline $0 \%$ & $45 \pm 1$ & $388 \mathrm{gm}$ & $0 \mathrm{gm}$ & 55 \\
\hline $1 \%$ & $44 \pm 1$ & $380 \mathrm{gm}$ & $4 \mathrm{gm}$ & 55 \\
\hline $2 \%$ & $43 \pm 1$ & $371 \mathrm{gm}$ & $7 \mathrm{gm}$ & 55 \\
\hline $3 \%$ & $42 \pm 1$ & $362 \mathrm{gm}$ & $10 \mathrm{gm}$ & 55 \\
\hline $4 \%$ & $41 \pm 1$ & $354 \mathrm{gm}$ & $14 \mathrm{gm}$ & 55 \\
\hline $5 \%$ & $40 \pm 1$ & $345 \mathrm{gm}$ & $17 \mathrm{gm}$ & 55 \\
\hline $6 \%$ & $39 \pm 1$ & $336 \mathrm{gm}$ & $20 \mathrm{gm}$ & 55 \\
\hline $7 \%$ & $38 \pm 1$ & $328 \mathrm{gm}$ & $22 \mathrm{gm}$ & 55 \\
\hline $8 \%$ & $37 \pm 1$ & $319 \mathrm{gm}$ & $25 \mathrm{gm}$ & 55 \\
\hline $9 \%$ & $36 \pm 1$ & $311 \mathrm{gm}$ & $27 \mathrm{gm}$ & 55 \\
\hline $10 \%$ & $35 \pm 1$ & $302 \mathrm{gm}$ & $30 \mathrm{gm}$ & 55 \\
\hline
\end{tabular}

Step 3: Hydraulic press In the hydraulic press the material obtained from Hand lay-up method is placed for the hardening purpose. Heat supplied is of around $600^{\circ} \mathrm{C}$ with a pressure of 1 bar for more than half an hour. Then it is removed from hydraulic press and kept for cooling till it comes to room temperature.

Step 4: Post Curing The post-cure involves increasing the laminate temperature after the initial room temperature cure, which increases the amount of cross linking of the molecules that can take place. To some degree this post-cure will occur naturally at warm room temperatures, but higher properties and shorter post-cure times will be obtained if elevated temperatures are used:

- $\quad 50^{\circ} \mathrm{C}-30 \mathrm{Min}$

- $\quad 70^{\circ} \mathrm{C}-60 \mathrm{Min}$

- $85^{\circ} \mathrm{C}-120 \mathrm{Min}$

\section{Burn-Out Test}

This test is carried to find out the weight fraction of the Fibers and matrix in a composite. Steps:

- Small pieces of the composite are to be cut from different locations

- Weigh the empty ceramic boats

- Weigh the boats with composite
- Place the boats with composite in a furnace at a temperature of around $600^{\circ} \mathrm{C}$ for duration of 45 to $60 \mathrm{~min}$

- Weight the boats with fibers

The laminate is prepared using the procedure described previously the laminate is trimmed at all the four edges. The specimens were cut from this laminate hence markings were made on the laminate using the parallel bars and a combination square as shown in the Fig. 2. Figure 3 shows the ready samples to be tested. The compression after impact test requires a perfect rectangular specimen with the opposite sides being perfectly parallel; at least the edges which are compressed should be parallel. Hence due care was taken in specimen preparation during the course of the work. The marked laminate was cut using a band saw of 24 tpi during the cutting process it was ensured that the cut is given exactly at a uniform rate and exactly on the lines which were marked. Around 15 specimen were obtained in each laminate subsequently the edges of each specimen were rubbed using a coarse sand paper (cloth emery) of J297 grade; to ensure that the edges do not contain any defects, as these defects may itself induce failure or edge crushing during the time of tensional testing. Once the specimens were ready inspection was carried on each specimen to check whether the specimen is perfectly rectangular and also to ensure that the opposite edges are perfectly parallel. The specimen of size $400 \times 400 \mathrm{~mm}$ which is inspected is then used for further testing as shown in Fig. 2. 

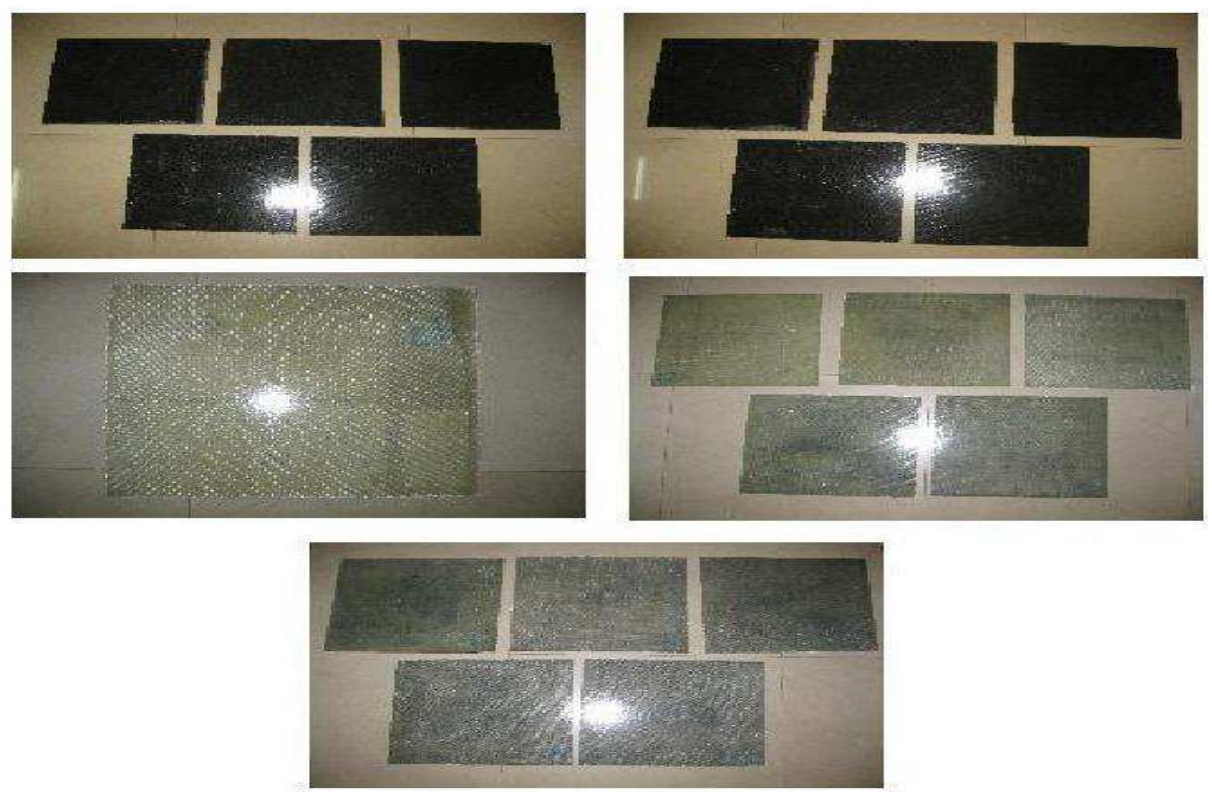

Fig. 2. Fabricated laminates of standard size (without filler, Graphite filler and SIC filler)

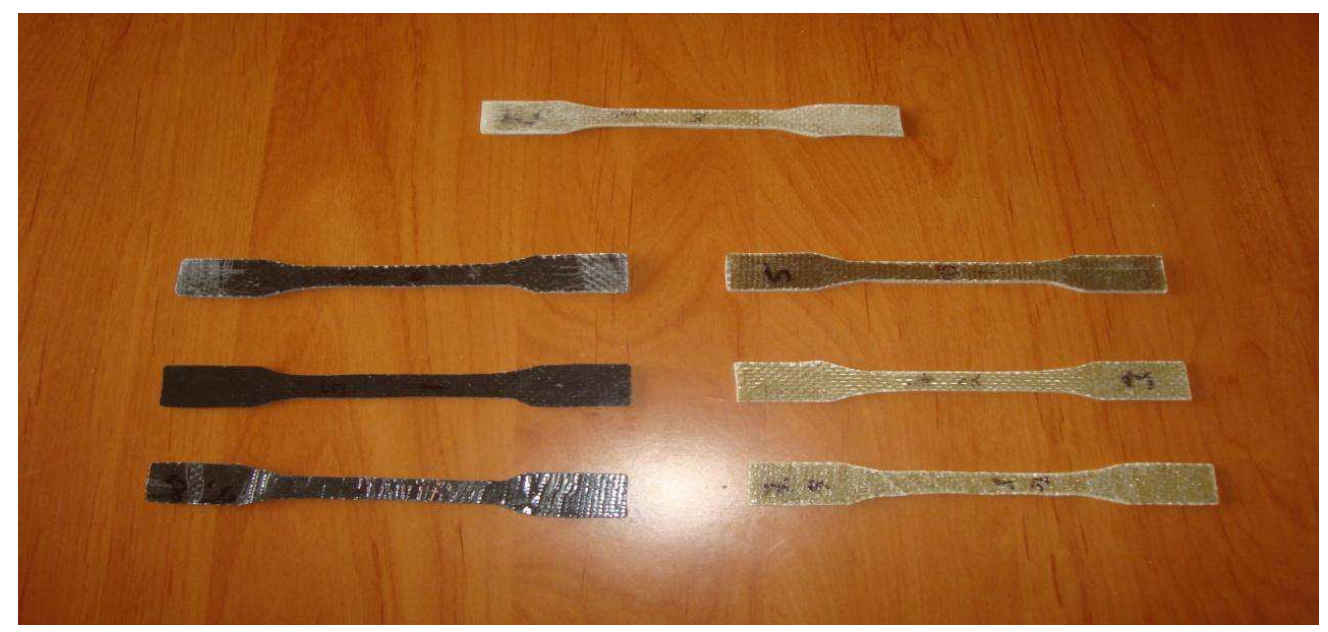

Fig. 3. Tensile specimen for testing-Without filler (centre), Graphite series (left), silicon series (right)

\section{Testing and Calculations}

\section{Tensile Test (ASTM D 638M)}

Whenever some external forces acts on a body, it undergoes some deformations if a body is stressed within its elastic limit, the deformation completely disappears as soon as the forces are removed. And beyond the elastic limit, the deformation does not disappear completely, even after the removal of the forces and there remains some residual deformation. This test method is designed to produce tensile properties such as tensile strength, modulus of elasticity (young's modulus) and percentage of elongation for control and specification of composite materials. These data are useful for qualitative characterization, engineering design and $R \& D$ purposes. Tensile test, in a broad sense is measurement of the ability of a material to withstand forces that trend to pull it apart and to determine to what extent the material stretches before breaking. Tensile modulus, an indication of the relative stiffness can be determined from stress strain diagram. For every test three sample specimens were prepared. Table 1 shows testing compositions and calculations.

\section{Procedure}

- Measure the width and thickness of specimens with a suitable micrometer to the nearest $0.02 \mathrm{~mm}$ at several points along their narrow sections within the 
gauge boundaries. Record the minimum values of cross sectional area so determined

- Mark gauge length on the specimen

- Set the grip separation speed of the machine; place the specimen straight in the grips

- Tighten the grips evenly and firmly to the extent necessary to prevent slippage of the specimen during test and not the point where the specimen would be crushed

- Start the machine and record the load and extension curve

- Record the load and extension at yield and break point

\section{Results}

Superimposed Graphs of Tensile-Graphite Series

Superimposed Graphs of Tensile Silicon Series

The results obtained from test series involving an elongation history are shown in Fig. 4-24. The dynamic flow curve of the interrupted strain rate jump tests of dynamic testing. For every sample, three trails have been done and it's shown in each diagram. The lines on these diagrams represent the stress-elongation relationship obtained by interrupting the dynamic-tensile tests at different levels of strain rate change.
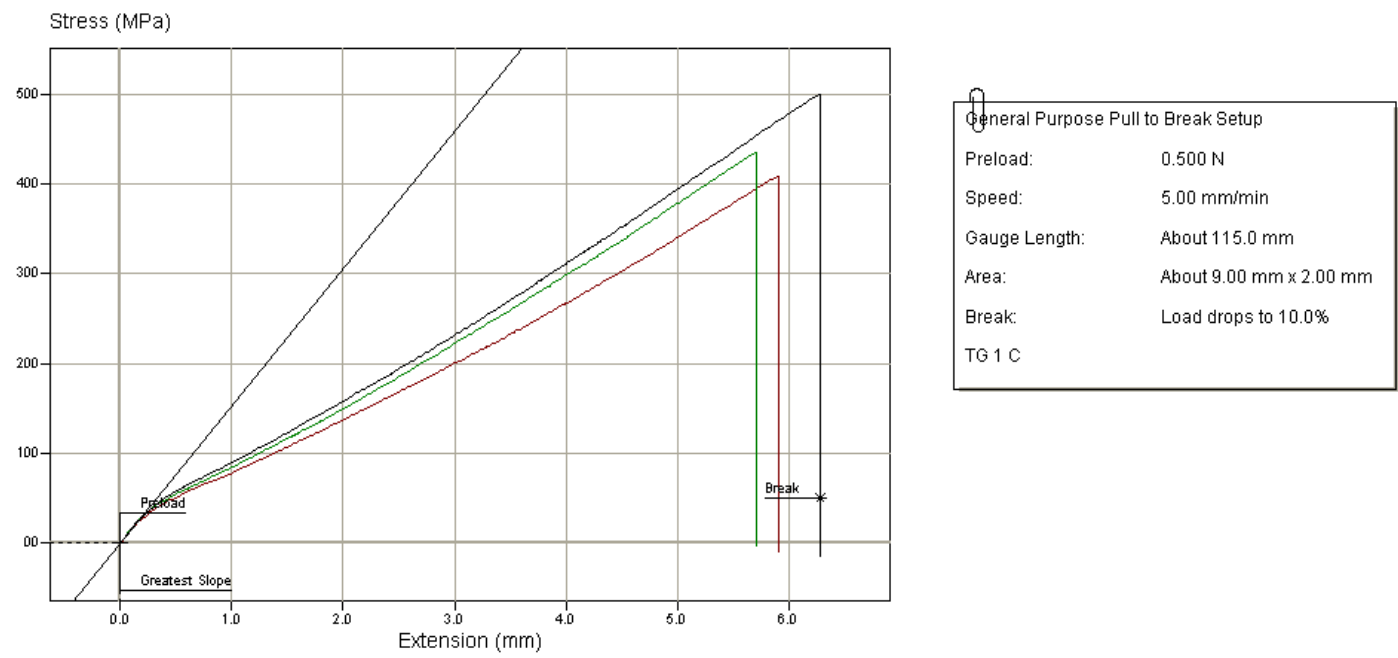

Fig. 4. Superimposed graphs of tensile-graphite series TG1

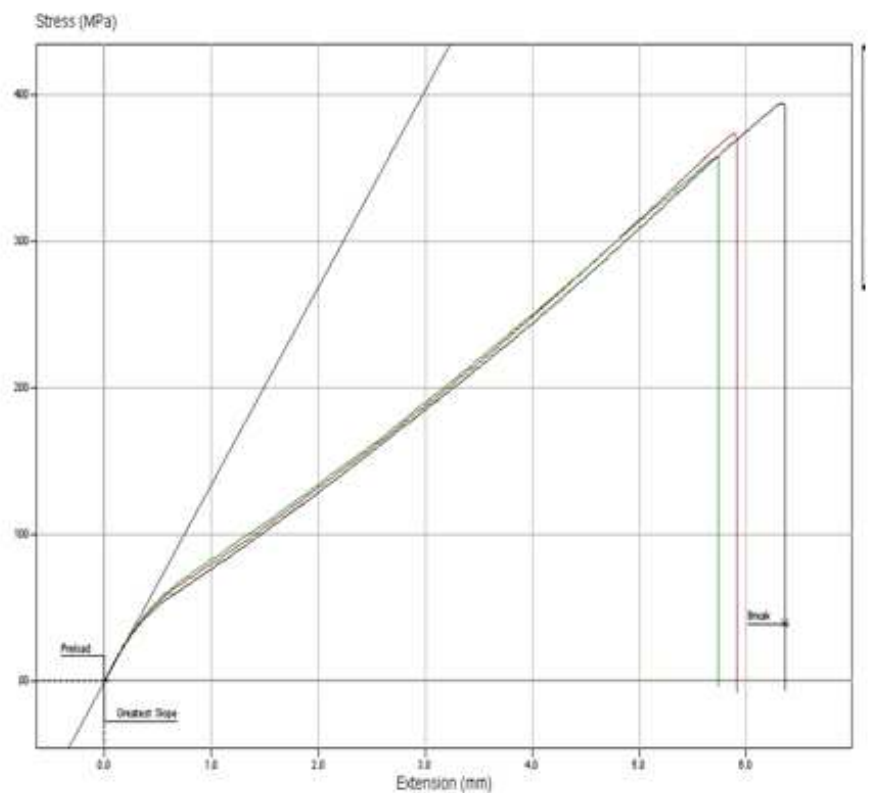

General Purpose Pull to Break Setup Preload: $0.500 \mathrm{~N}$ Speed: $5.00 \mathrm{~mm} / \mathrm{min}$ Gauge Length: About $115.0 \mathrm{~mm}$ Area: About $10.0 \times 2.25 \mathrm{~mm}$ Break: Load drops to $10.0 \%$

Fig. 5. Superimposed graphs of tensile-graphite series TG2 


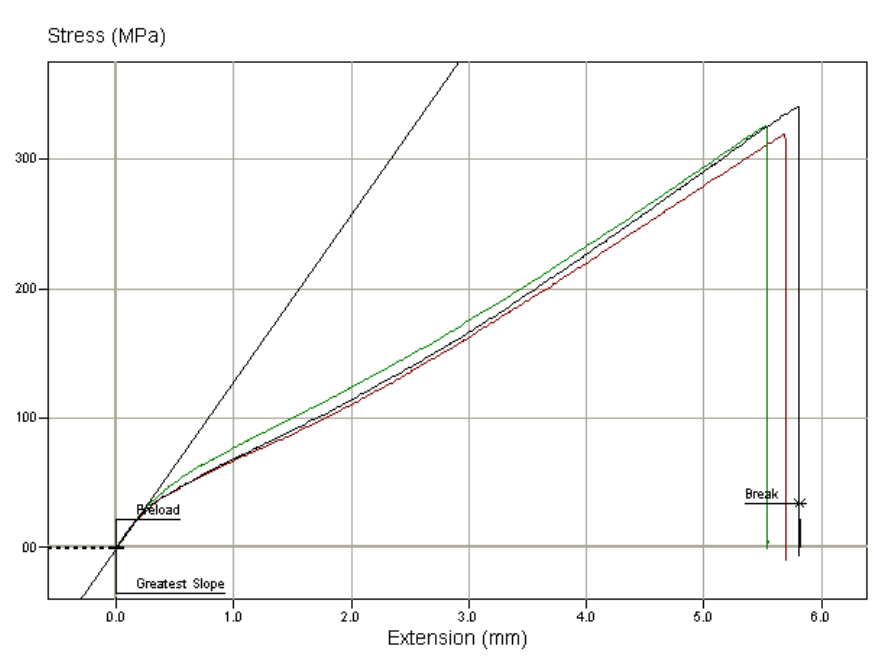

\begin{tabular}{|ll|}
\hline Géneral Purpose Pull to Break Setup \\
Preload: & $0.500 \mathrm{~N}$ \\
Speed: & $5.00 \mathrm{~mm} / \mathrm{min}$ \\
Gauge Length: & About $115.0 \mathrm{~mm}$ \\
Area: & About $10.0 \mathrm{~mm} \times 2.25 \mathrm{~mm}$ \\
Ereak: & Load drops to $10.0 \%$ \\
TG3C & \\
\hline
\end{tabular}

Fig. 6. Superimposed graphs of tensile-graphite series TG3

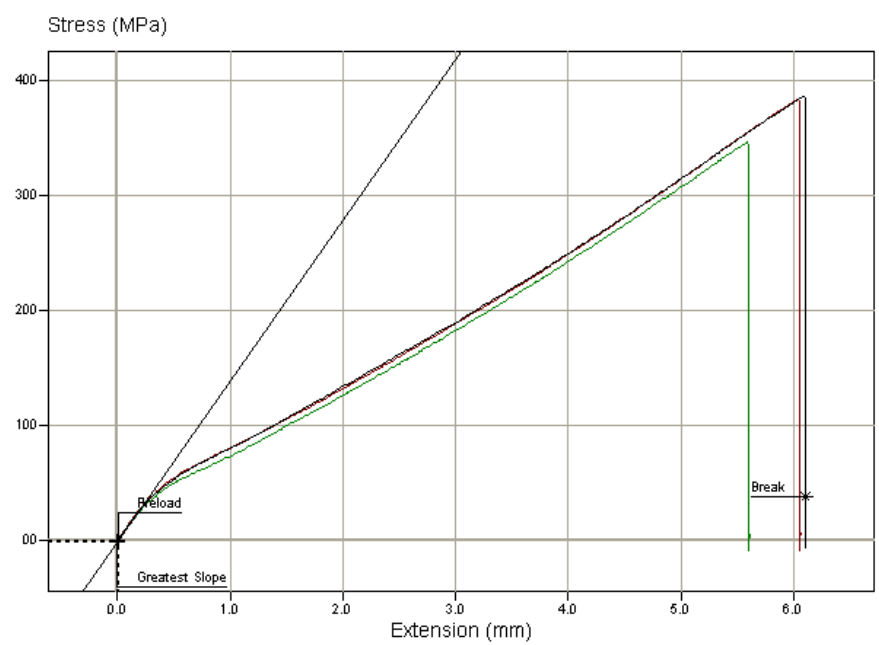

\begin{tabular}{|ll|}
\hline Gegneral Purpose Pull to Break Setup \\
Preload: & $0.500 \mathrm{~N}$ \\
Speed: & $5.00 \mathrm{~mm} / \mathrm{min}$ \\
Gauge Length: & About $115.0 \mathrm{~mm}$ \\
Area: & About $10.0 \mathrm{~mm} \times 2.25 \mathrm{~mm}$ \\
Break: & Load drops to $10.0 \%$ \\
TG4C & \\
\hline
\end{tabular}

Fig. 7. Superimposed graphs of tensile-graphite series TG4

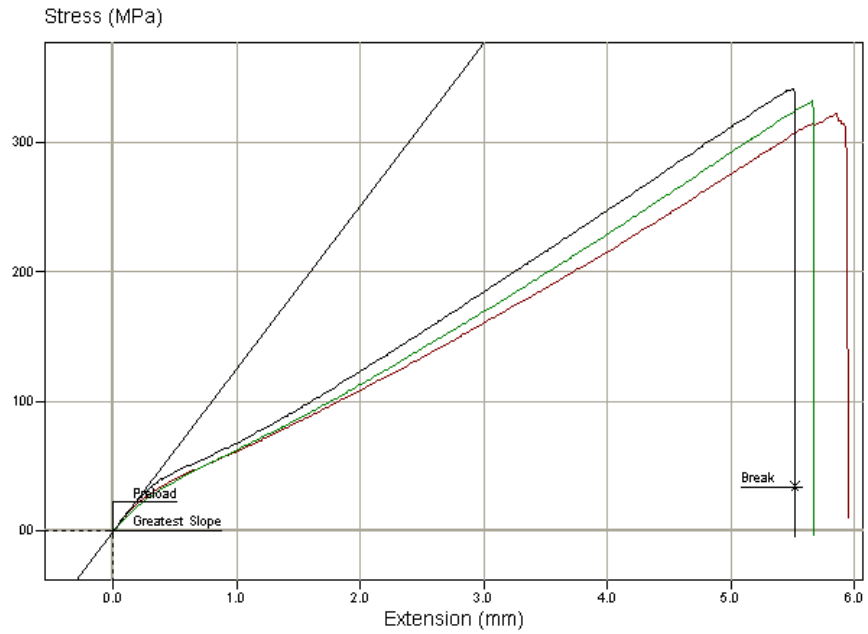

\begin{tabular}{|ll|}
\hline Genneral Purpose Pull to Break Setup \\
Preload: & $0.500 \mathrm{~N}$ \\
Speed: & $5.00 \mathrm{~mm}$ imin \\
Gauge Length: & About $115.0 \mathrm{~mm}$ \\
Area: & About $10.0 \mathrm{~mm} \times 2.25 \mathrm{~mm}$ \\
Break: & Load drops to $10.0 \%$ \\
TG5C & \\
\hline
\end{tabular}

Fig. 8. Superimposed graphs of tensile-graphite series TG5 
Vikram G. Kamble and Naveen Kumar L. / American Journal of Engineering and Applied Sciences 2016, 9 (1): 17.30 DOI: 10.3844/ajeassp.2016.17.30

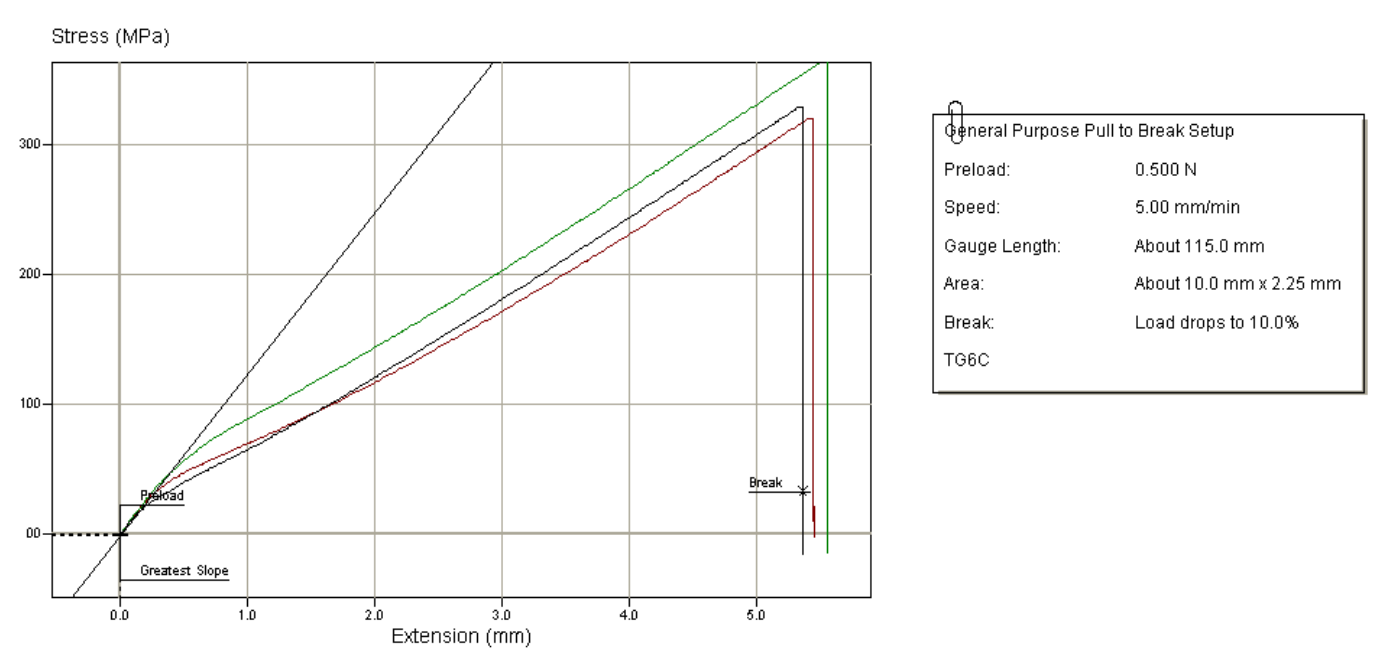

Fig. 9. Superimposed graphs of tensile-graphite series TG6

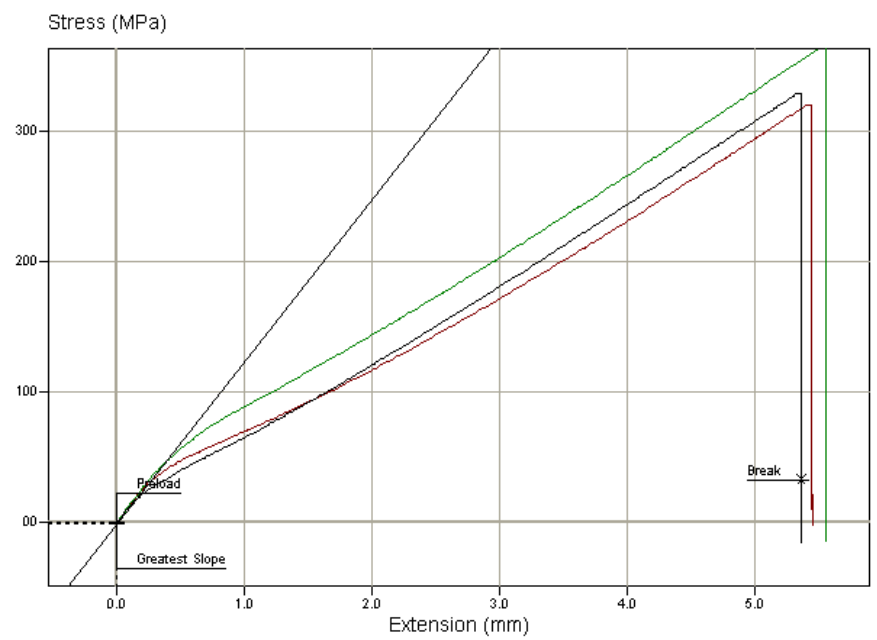

\begin{tabular}{|ll|}
\hline Getneral Purpose Pull to Break Setup \\
Preload: & $0.500 \mathrm{~N}$ \\
Speed: & $5.00 \mathrm{~mm}$ imin \\
Gauge Length: & About $115.0 \mathrm{~mm}$ \\
Area: & About $10.0 \mathrm{~mm} \times 2.25 \mathrm{~mm}$ \\
Break: & Load drops to $10.0 \%$ \\
TG6C & \\
\hline
\end{tabular}

Fig. 10. Superimposed graphs of tensile-graphite series TG7

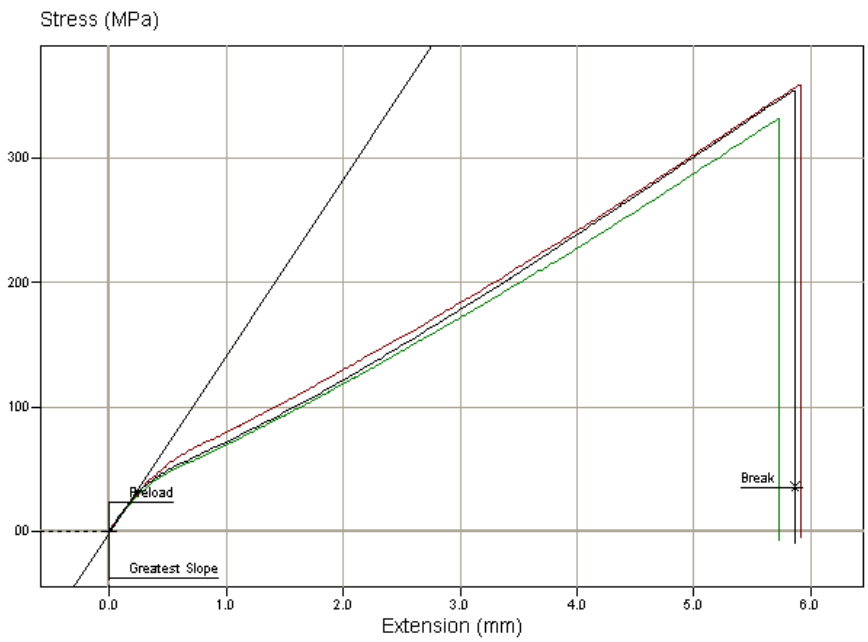

\begin{tabular}{|c|c|}
\hline \multicolumn{2}{|c|}{ foneral Purpose Pull to Break Setup } \\
\hline Preload: & $0.500 \mathrm{~N}$ \\
\hline Speed: & $5.00 \mathrm{~mm} / \mathrm{min}$ \\
\hline Gauge Length: & About $115.0 \mathrm{~mm}$ \\
\hline Area: & About $10.0 \mathrm{~mm} \times 2.25 \mathrm{~mm}$ \\
\hline Break: & Load drops to $10.0 \%$ \\
\hline TGBC & \\
\hline
\end{tabular}

Fig. 11. Superimposed graphs of tensile-graphite series TG8 
Vikram G. Kamble and Naveen Kumar L. / American Journal of Engineering and Applied Sciences 2016, 9 (1): 17.30 DOI: 10.3844/ajeassp.2016.17.30

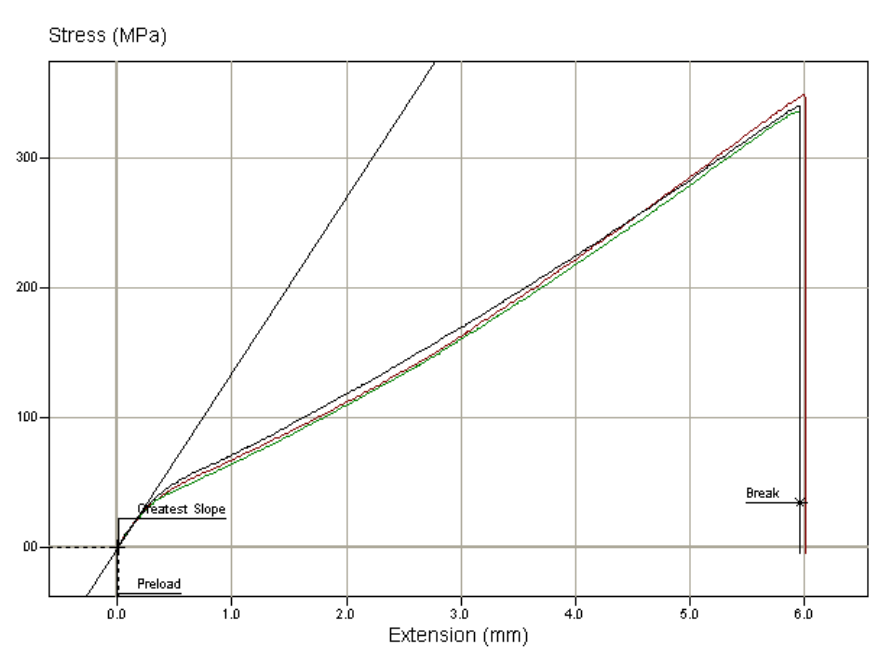

\begin{tabular}{|ll|}
\hline Gegneral Purpose Pull to Break Setup \\
Preload: & $0.500 \mathrm{~N}$ \\
Speed: & $5.00 \mathrm{~mm} / \mathrm{min}$ \\
Gauge Length: & About $115.0 \mathrm{~mm}$ \\
Area: & About $10.0 \mathrm{~mm} \times 2.25 \mathrm{~mm}$ \\
Break: & Load drops to $10.0 \%$ \\
TGgC & \\
\hline
\end{tabular}

Fig. 12. Superimposed graphs of tensile-graphite series TG9

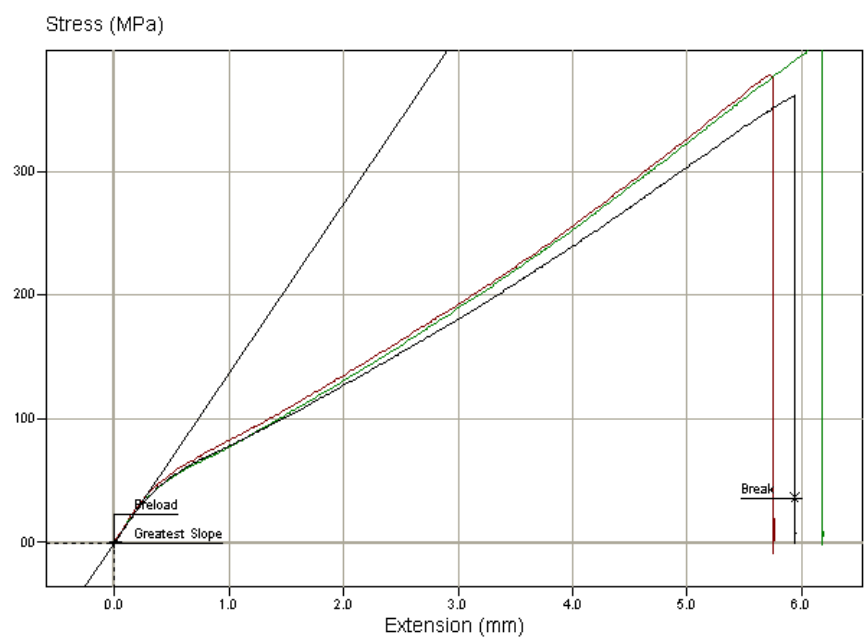

\begin{tabular}{|ll|}
\hline Afneral Purpose Pull to Break Setup \\
Preload: & $0.500 \mathrm{~N}$ \\
Speed: & $5.00 \mathrm{~mm} / \mathrm{min}$ \\
Gauge Length: & About $115.0 \mathrm{~mm}$ \\
Area: & About $10.0 \mathrm{~mm} \times 2.25 \mathrm{~mm}$ \\
Break: & Load drops to $10.0 \%$ \\
TG10C & \\
\hline
\end{tabular}

Fig. 13. Superimposed graphs of tensile-graphite series TG10

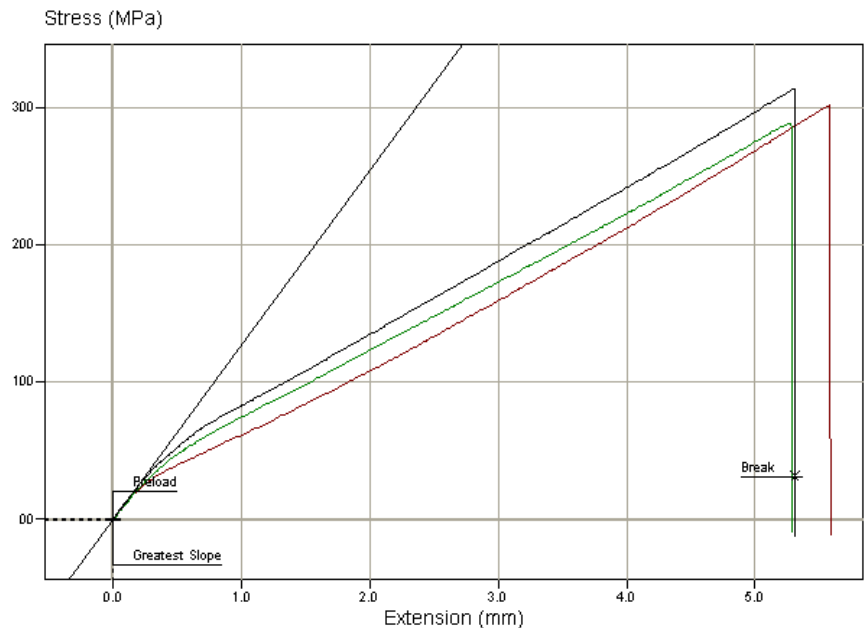

\begin{tabular}{|c|c|}
\hline \multicolumn{2}{|c|}{ General Purpose Pull to Break Setup } \\
\hline Preload: & $0.500 \mathrm{~N}$ \\
\hline Speed: & $5.00 \mathrm{~mm} / \mathrm{min}$ \\
\hline Gauge Length: & About $115.0 \mathrm{~mm}$ \\
\hline Area: & About $10.0 \mathrm{~mm} \times 2.75 \mathrm{~mm}$ \\
\hline Break: & Load drops to $10.0 \%$ \\
\hline TS1C & \\
\hline
\end{tabular}

Fig. 14. Superimposed graphs of tensile silicon series TS1 
Vikram G. Kamble and Naveen Kumar L. / American Journal of Engineering and Applied Sciences 2016, 9 (1): 17.30 DOI: 10.3844/ajeassp.2016.17.30

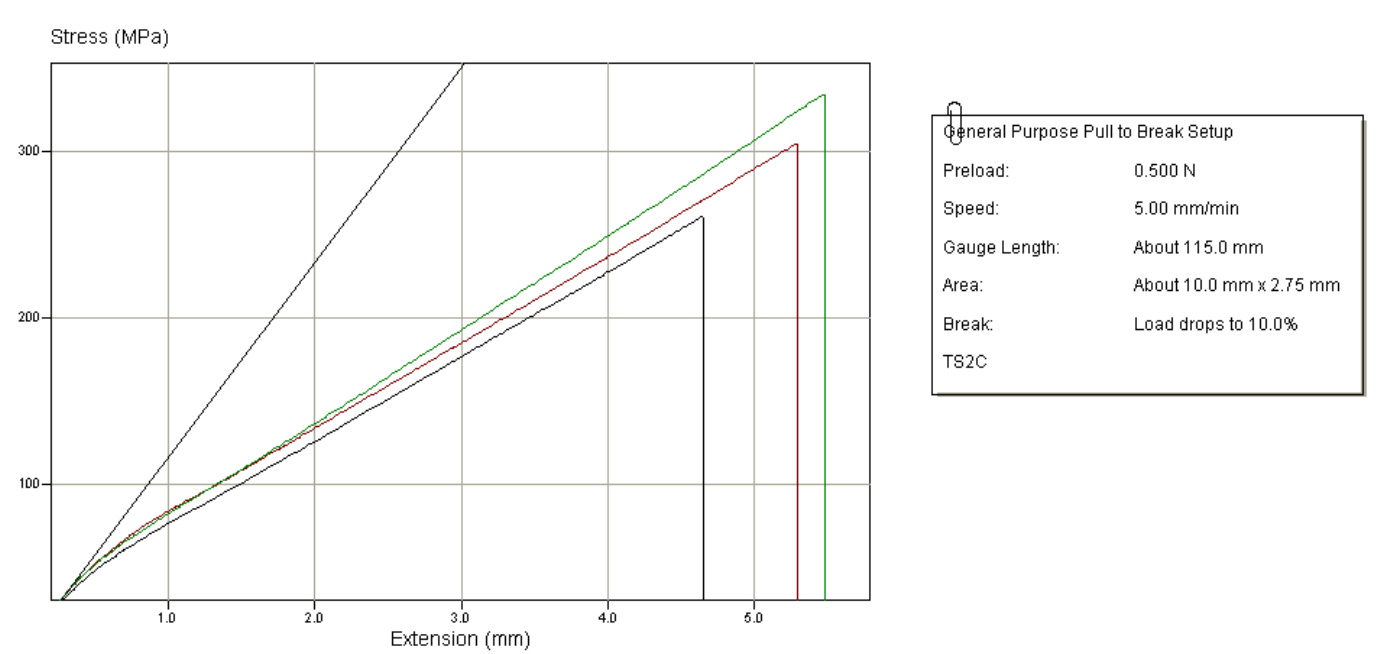

Fig. 15. Superimposed graphs of tensile silicon series TS2

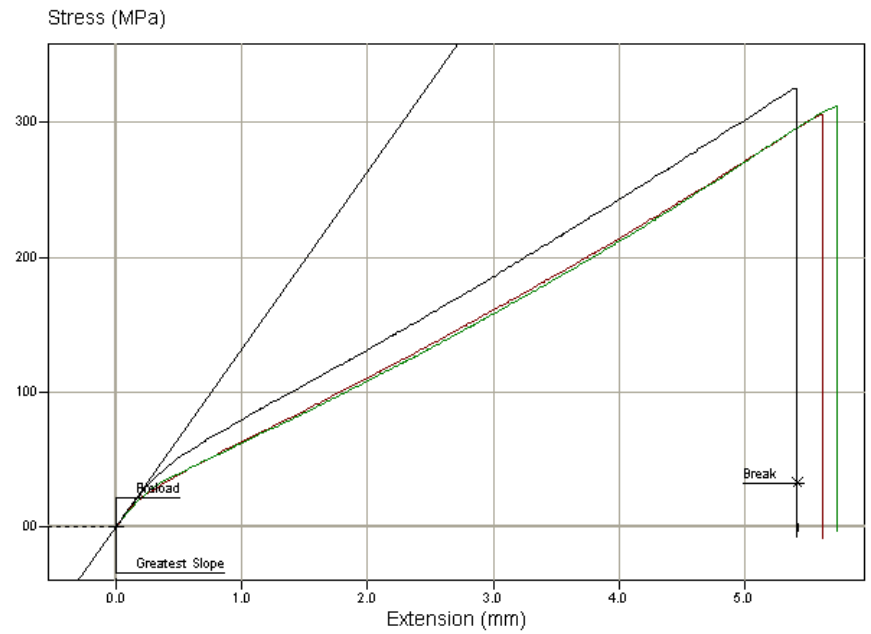

\begin{tabular}{|ll|}
\hline General Purpose Pull to Break Setup \\
Preload: & $0.500 \mathrm{~N}$ \\
Speed: & $5.00 \mathrm{~mm} / \mathrm{min}$ \\
Gauge Length: & About $115.0 \mathrm{~mm}$ \\
Area: & About $10.0 \mathrm{~mm} \times 2.50 \mathrm{~mm}$ \\
Break: & Load drops to $10.0 \%$ \\
TS3C & \\
\hline
\end{tabular}

Fig. 16. Superimposed graphs of tensile silicon series TS3

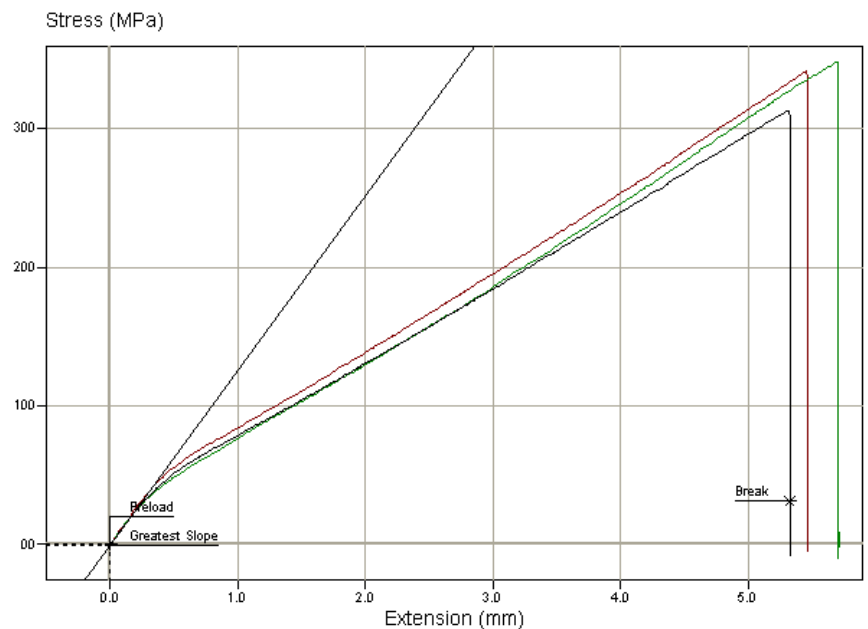

\begin{tabular}{|ll|}
\hline Getneral Purpose Pull to Break Setup \\
Preload: & $0.500 \mathrm{~N}$ \\
Speed: & $5.00 \mathrm{~mm} / \mathrm{min}$ \\
Gauge Length: & About $115.0 \mathrm{~mm}$ \\
Area: & About $10.0 \mathrm{~mm} \times 2.50 \mathrm{~mm}$ \\
Break: & Load drops to $10.0 \%$ \\
TS4C & \\
\hline
\end{tabular}

Fig. 17. Superimposed graphs of tensile silicon series TS4 


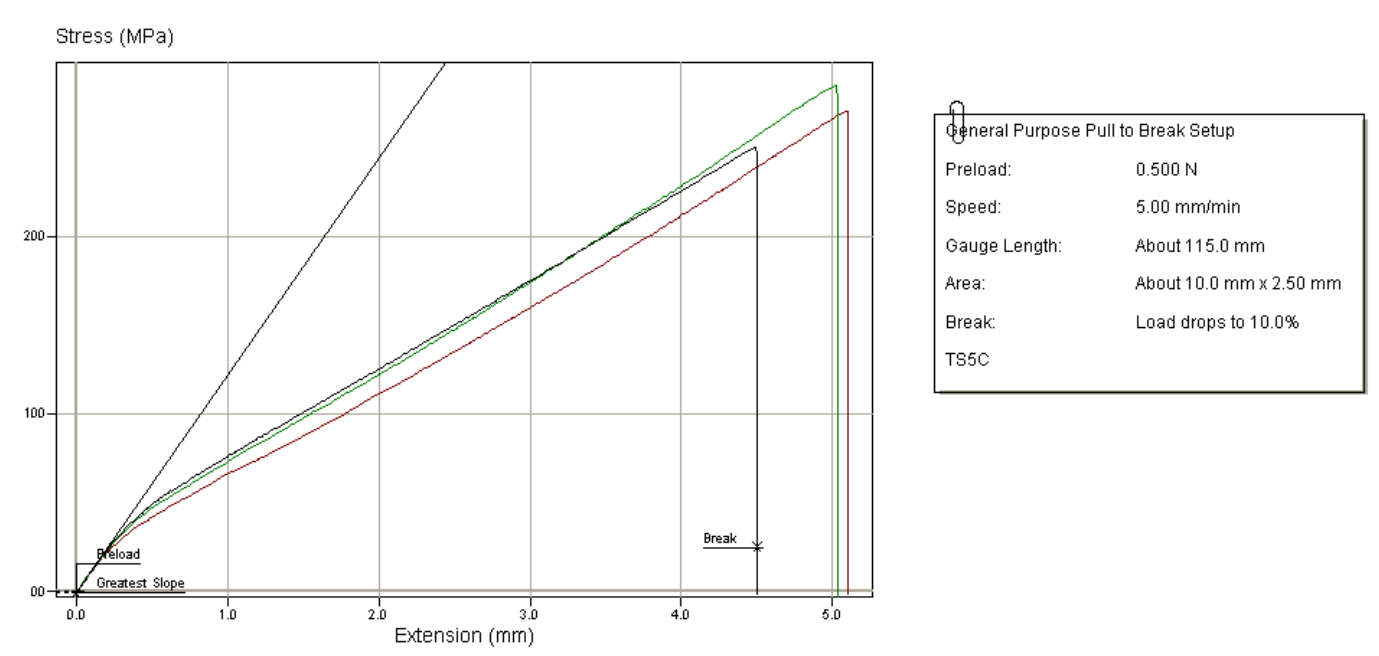

Fig. 18. Superimposed graphs of tensile silicon series TS5

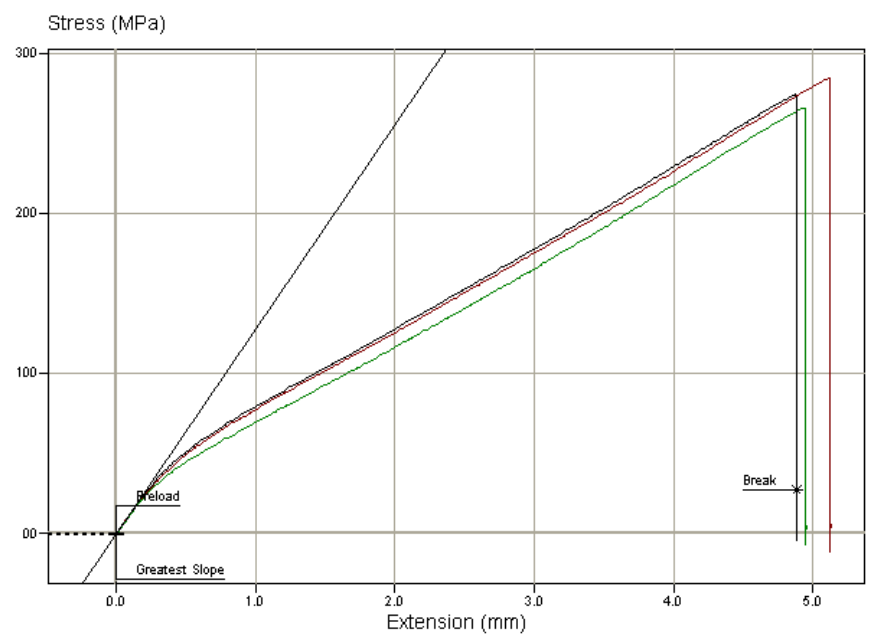

\begin{tabular}{ll|}
\hline General Purpose Pull to Break Setup \\
Preload: & $0.500 \mathrm{~N}$ \\
Speed: & $5.00 \mathrm{~mm} / \mathrm{min}$ \\
Gauge Length: & About $115.0 \mathrm{~mm}$ \\
Area: & About $10.0 \mathrm{~mm} \times 2.50 \mathrm{~mm}$ \\
Break: & Load drops to $10.0 \%$ \\
TS6C & \\
\hline
\end{tabular}

Fig. 19. Superimposed graphs of tensile silicon series TS6

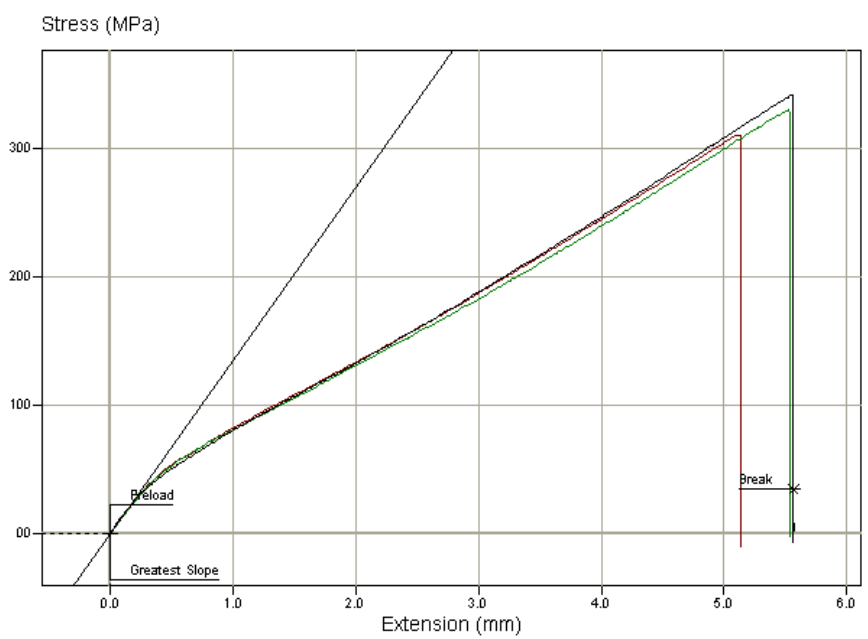

\begin{tabular}{|ll|}
\hline Gefneral Purpose Pull to Break Setup \\
Preload: & $0.500 \mathrm{~N}$ \\
Speed: & $5.00 \mathrm{~mm} / \mathrm{min}$ \\
Gauge Length: & About $115.0 \mathrm{~mm}$ \\
Area: & About $10.0 \mathrm{~mm} \times 2.50 \mathrm{~mm}$ \\
Break: & Load drops to $10.0 \%$ \\
TS7C & \\
\hline
\end{tabular}

Fig. 20. Superimposed graphs of tensile silicon series TS7 
Vikram G. Kamble and Naveen Kumar L. / American Journal of Engineering and Applied Sciences 2016, 9 (1): 17.30 DOI: 10.3844/ajeassp.2016.17.30

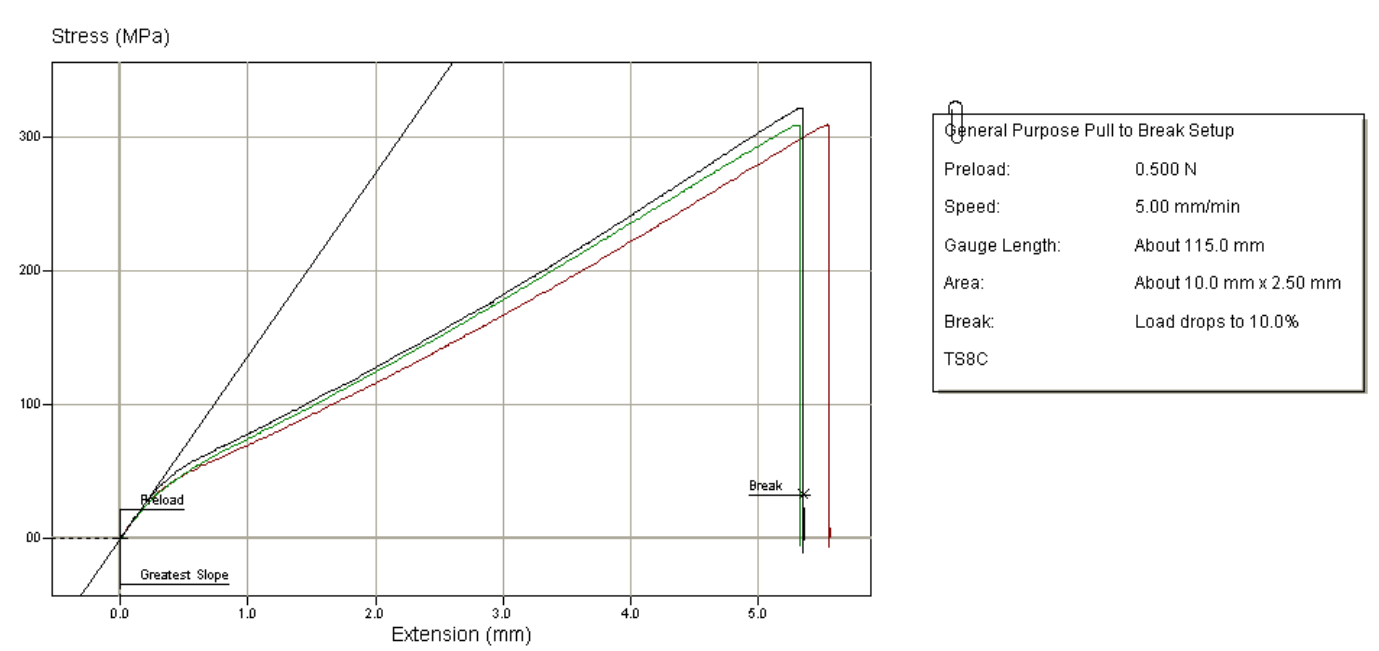

Fig. 21. Superimposed graphs of tensile silicon series TS8

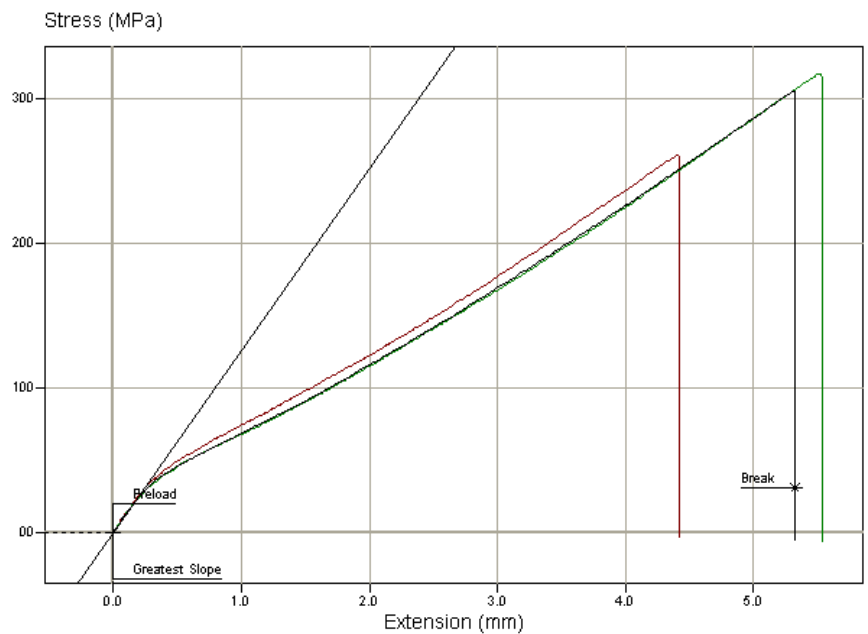

\begin{tabular}{|ll|}
\hline Genneral Purpose Pull to Break Setup \\
Preload: & $0.500 \mathrm{~N}$ \\
Speed: & $5.00 \mathrm{~mm} / \mathrm{min}$ \\
Gauge Length: & About $115.0 \mathrm{~mm}$ \\
Area: & About $10.0 \mathrm{~mm} \times 2.50 \mathrm{~mm}$ \\
Ereak: & Load drops to $10.0 \%$ \\
TS9C & \\
\hline
\end{tabular}

Fig. 22. Superimposed graphs of tensile silicon series TS9

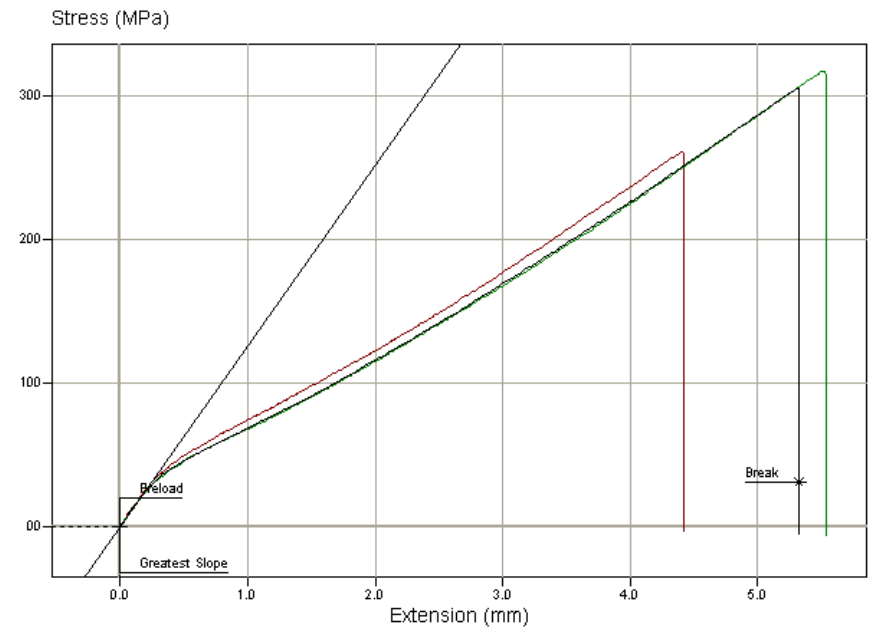

\begin{tabular}{|ll|}
\hline Gqneral Purpose Pull to Break Setup \\
Preload: & $0.500 \mathrm{~N}$ \\
Speed: & $5.00 \mathrm{~mm} / \mathrm{min}$ \\
Gauge Length: & About $115.0 \mathrm{~mm}$ \\
Area: & About $10.0 \mathrm{~mm} \times 2.50 \mathrm{~mm}$ \\
Break: & Load drops to $10.0 \%$ \\
TS9C & \\
\hline
\end{tabular}

Fig. 23. Superimposed graphs of tensile silicon series TS10 


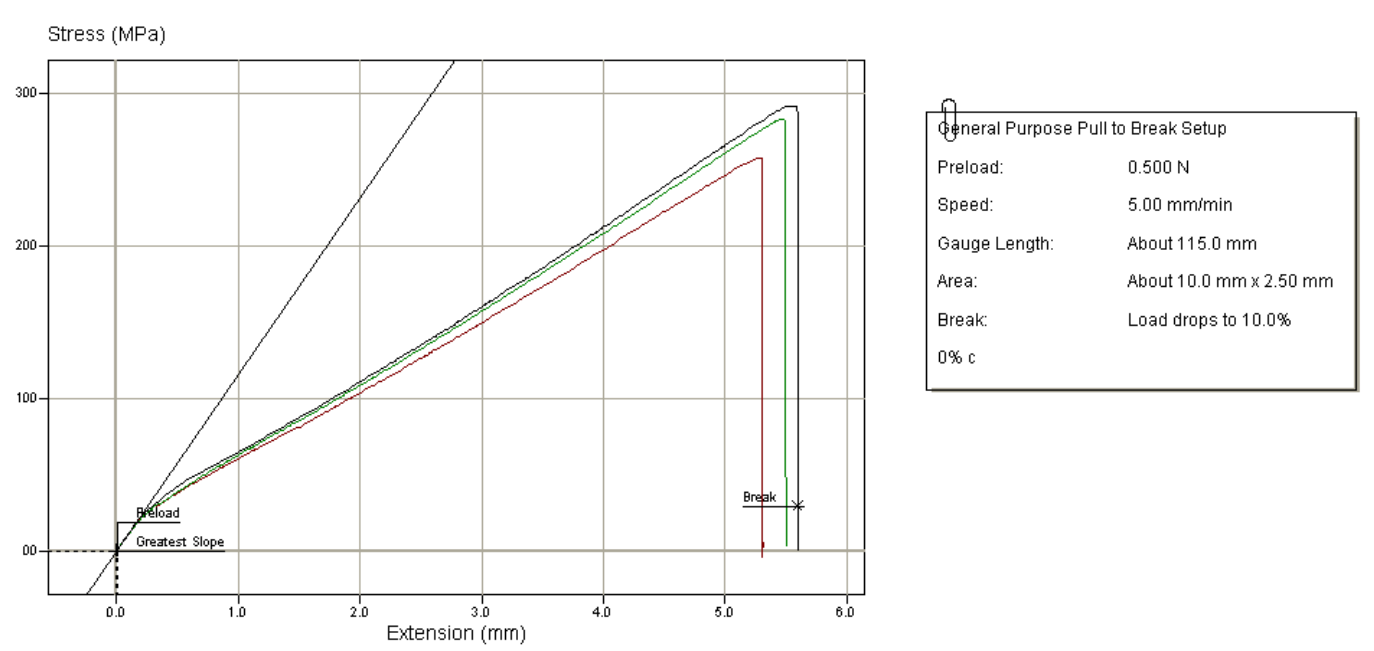

Fig. 24. Without filler

\section{Tensile Strength}

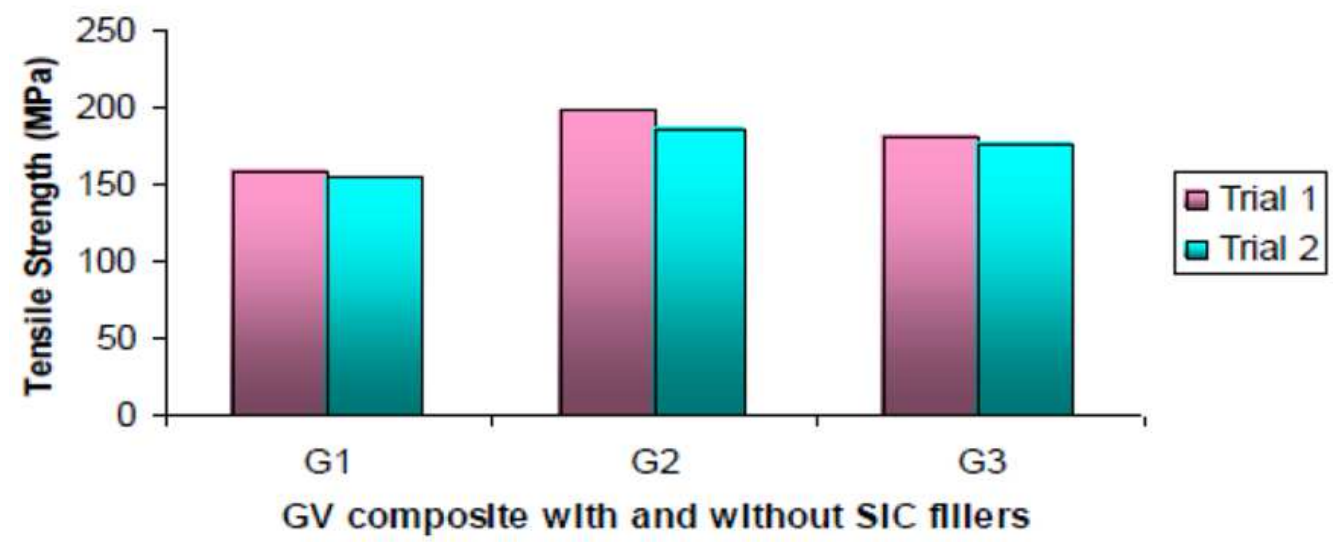

Fig. 25. Standard graph showing tensile strength for different percentage of filler

Young's Modulus

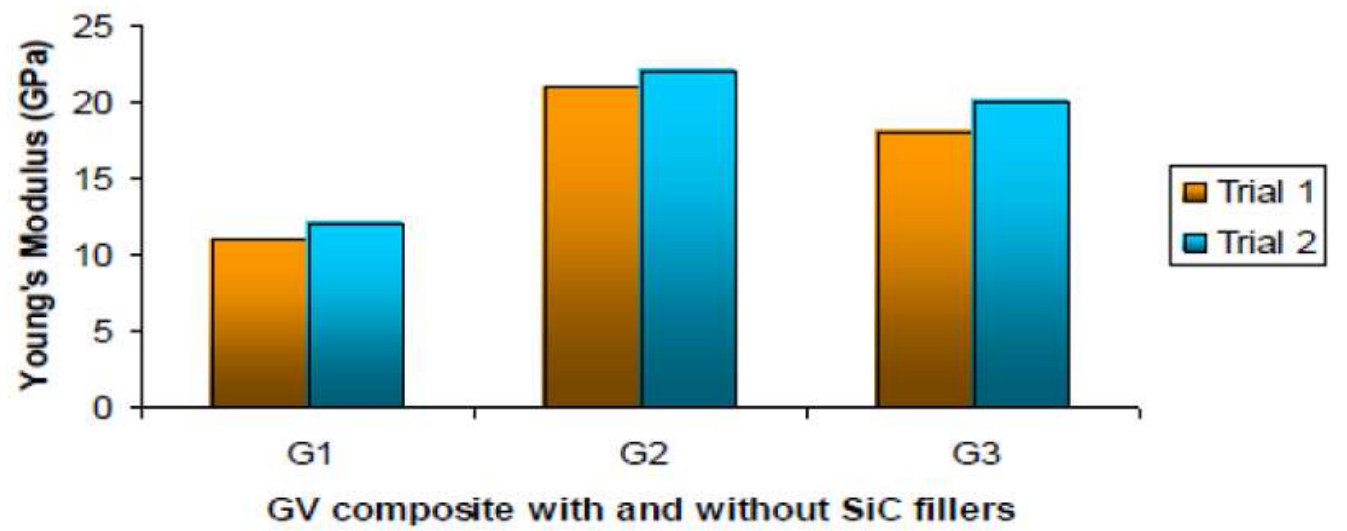

Fig. 26. Standard graph showing young's modulus for different percentage of filler 
The quasi-static to dynamic strain rate shown in Fig. 4-24, because of strain extensional in material takes place. For prestrains less than about $1 \mathrm{~mm}$, the dynamic reloading curve is characterized by a well defined yield point whose level is higher than the maximum reached in quasi-static prestraining, but which is very close to the flow stress level reached at the same strain in these tests conducted exclusively at the dynamic rate. In general trend of a quasi-static reloading behaviour is complex and presumably governed, like with many other composites by strain ageing phenomenon, which depend on dynamic prestrains. And further more the quasi-static curves are also show phenomenon of dynamic strain ageing manifested by serrations along the flow curves. It is interesting to note that the same strain ageing phenomenon was also observed on static prestraining Fig. 4-24.

The present experimental results put in evidence that the static strain ageing effects are present in quasi-static and in the dynamic reloading flow curves obtained after prestraining at a different strain rate, but are practically absent in the reloading flow curves obtained after prestraining at the same rat. This fact would reflect the difference in the governing deformation modes and the microstructures developed during high and low rate prestraining. It is the passage from one deformation mode to the other which provokes the state and the dynamic strain ageing instabilities.

Figure 25 shows the Standard graph of tensile strength for different percentage of filler of G1, G2 and G3. And it is observed that the G2 exhibits the highest tensile strength. Similarly young's modulus is highest in the G2 which can be seen in Fig. 26.

\section{Conclusion}

Test specimens of constant fibre weight fraction (63 to $65 \%$ ) and thickness $3 \mathrm{~mm}$ were prepared to study the effect of mechanical properties on the tensile strength of the Glass/epoxy composite. Tensile tests were carried out on these test specimens with different energy levels. The properties reduced from tension tests on composite materials are effective (averaged) properties. Tensile test, in a broad sense is measurement of the ability of a material to withstand forces that trend to pull it apart and to determine to what extent the material stretches before breaking. Tensile modulus, an indication of the relative stiffness can be determined from stress strain diagram. The residual tensile strengths of the damaged test specimens were obtained and their relationship with different incident energy levels, delamination areas etc. were studied:

- Introduction of graphite and $\mathrm{SiC}$ fillers in E-glass reinforced $\mathrm{GV}$ composites, improved in the mechanical properties, thus emphasizing the importance for the need to introduce fillers into glass reinforced GV composites

- Addition of fillers increases tensile strength, modulus, flexural strength, impact strength and hardness of Glass Vinyl ester composites

- Correlating the tensile results and observations of the fractured surface of the graphite filled GV composites, it is verified that the interfacial adhesion between fiber/matrix, which leads to, improved mechanical properties

- The tests showed linear elastic behaviour and brittle fracture for the test samples along with fibers in a composite fail at different stress levels as the applied tensile load increases

- The friction and slide wear behaviour of $7.5 \mathrm{wt} . \%$ graphite filled glass-epoxy composite is better compared to glass epoxy composites with lower graphite filler content

- The experimental results show that the self lubricating graphite filled G-E composite material investigated may be an adequate candidate for wear application in bearings

\section{Acknowledgement}

We are very grateful to SJCE, Mysore (INDIA) for providing all facilities for testing our samples.

\section{Author's Contributions}

Vikram G Kamble: Planned the work and conducted the experiments.

Naveen Kumar L: Did result analysing and all other mouse work.

\section{Conflicts of Interest}

Authors don't have conflicts of interest regarding publication of this manuscript.

\section{References}

Cha'o-Kuang, C. and T. Tzu-Li, 1997. The indirect measurement of tensile strength by the deterministic grey dynamic model DGDM. Int. J. Syst. Sci., 28: 683-690. DOI: 10.1080/00207729708929428

Cybulskaa, M. and B.C. Goswamib, 2001. Tensile behaviour of staple yarns. J. Textile Inst., 92: 26-37. DOI: $10.1080 / 00405000108659612$

Eldera, H.M., 1966. The tensile, compressive and bending moduli of some monofilament materials. J. Textile Inst. Transact., 57: T8-T14. DOI: $10.1080 / 19447026608662331$ 
Ismaila, H. and H.D. Rozman, 1998. Studies on the tensile properties of rubberwood fibre-natural rubber composites. Int. J. Polymeric Mater., 41: 325-333. DOI: $10.1080 / 00914039808041053$

Kalthoff, J.F., 2004. Characterization of the dynamic failure behaviour of a glass-fiber/vinyl-ester at different temperatures by means of instrumented Charpy impact testing. Composites, 35: 657-663. DOI: 10.1016/j.compositesb.2003.11.008

Kamble, V.G., S.G. Kamble and K.D. Ramesh, 2015. Prediction of frictional and wear behavior of aluminium matrix composites by artificial neural network. J. Molecular Eng. Mater., 2: 14500041450014. DOI: $10.1142 / \mathrm{S} 225123731450004 \mathrm{X}$

Pande, G.N., J. Middleton and B. Kralj, 1998. Measurement of tensile strain softening and its influence on bond tensile test results. Proceedings of the 4th International Symposium Computer Methods in Structural Masonry, (MAM' 00).

Stevanovica, D., S. Kalyanasundaramb, A. Lowe and Jar, P.Y.B. 2003. Mode I and mode II delamination properties of glass/vinyl-ester composite toughened by particulate modified interlayers. Compos. Sci. Technol., 63: 1949-1964.

DOI: $10.1016 / \mathrm{S} 0266-3538(03) 00162-3$
Surendranathan, A.O., M. Savitha and K.V. Sreenivasaprasad, 2008. Study on effect of incorporation of $\mathrm{SiC}$ fillers on Tensile and Flexural behavior of $\mathrm{GV}$ composites by experimental and simulation methods. MS\&T.

Suresha, B., 2003. The mechanical and tribological properties.

Swaminathan, G., K.N. Shivakumar and M. Sharpe, 2007. RETRACTED: Evaluation of specific properties of glass and carbon/vinyl ester composites. Composites, 39: 27-35.

DOI: 10.1016/j.compositesb.2007.02.012

Unal, H. and A. Mimaroglu, 2004. Influence of filler addition on the mechanical properties of nylon- 6 polymer. J. Reinforced Plast. Compos., 23: 461-469. DOI: $10.1177 / 0731684404031977$

Varada Rajulu, A., S.V. Sanjeev Kumar, G. Babu Rao, G.M. Shashidhara and J. He et al., 2002. Tensile properties of glass rovings/hydroxyl terminated polyester toughened epoxy composites. J. Reinforced Plast. Compos., 21: 1591-1596. DOI: $10.1177 / 0731684402021017494$

Wu, T.J. and H.T. Hahn, 1998. The bearing strength of e-glass/vinyl-ester composites fabricated by vartm. Comp. Sci. Technol., 58: 1519-1529. DOI: $10.1016 / \mathrm{S} 0266-3538(97) 00180-2$ 